\title{
Human immune response to the 18-kDa outer-membrane antigen of Vibrio cholerae
}

\author{
CARMEN V. SCIORTINO \\ Department of Pathology, Veterans Administration Medical Center and the University of Louisville, 800 Zorn Avenue, \\ Louisville, KY 40206, USA
}

\begin{abstract}
Summary. The serum IgG response of human volunteers challenged with Vibrio cholerae $\mathrm{O} 1$ was analysed for reactivity to $V$. cholerae $\mathrm{Ol}$ outer-membrane antigens by enzyme-linked immunosorbent assay (ELISA) and the immunoblot technique. Purified outer-membrane antigen preparations from vibrios grown in low-iron conditions were separated by SDS-PAGE. Specific immunoblot reactions of human sera showed that an 18-kDa antigen, cholera protective antigen, was the major antigen with which sera reacted. ELISA revealed an increase in antibody to the $18-\mathrm{kDa}$ antigen in nine of 10 challenged volunteers. This response was independent of the biotype and serotype of the $V$. cholerae $\mathrm{O} 1$ challenge strain. Cholera protective antigen appears to be one of the major outer-membrane antigens involved in the human immune response to infection with $V$. cholerae.
\end{abstract}

\section{Introduction}

Patients who recover from cholera become immune to re-infection; ${ }^{1}$ immunity is independent of the biotype and serotype of the infecting strain, ${ }^{2}$ suggesting that a common antigen may be expressed in all pathogenic Vibrio cholerae strains.

The cholera enterotoxin is primarily responsible for the characteristic "rice-water" stools of cholera. This toxin has been widely studied as a potential source of a cholera vaccine, but immunity induced during recovery from cholera is greater than immunity to the toxin. ${ }^{3,4}$ Attenuated $V$. cholerae vaccines in which toxin production has been genetically deleted provide at least $50 \%$ protection from re-infection..$^{3-7}$ This implies that another antigen may provide the stimulus against re-infection with $V$. cholerae.

One genetically engineered non-toxigenic strain, $V$. cholerae CVD $103 \mathrm{HgR}$ (tox $A^{-} B^{+}$), gave $62 \%$ protective efficacy against subsequent challenge with virulent $V$. cholerae in a North American volunteer trial in medical students. ${ }^{7}$ In a trial of this vaccine in Thailand, where epidemic cholera exists, ${ }^{8} 11$ of 12 vaccinees developed serum vibriocidal titres (the best immunological correlate of protection) and nine showed a serum antitoxin response. The differences in antibacterial versus antitoxin immunity from those studies indicated that an unknown antigen was responsible for much of the antibacterial immunity.

We have developed monoclonal antibodies (MAbs) that recognise several outer-membrane antigens of $V$. cholerae, ${ }^{9}$ and protect suckling rabbits from lethal infection with $V$. cholerae ${ }^{10}$ Four different MAbs that recognised an $18-\mathrm{kDa}$ antigen provided $98 \%$ protection from disease, whereas MAbs recognising lipopolysaccharide (LPS) or other outer-membrane antigens were only $20-40 \%$ protective. The antigen that reacted with the four protective MAbs was named cholera protective antigen (CPA).

In this study, ELISA and Western blotting were used to examine reactivity with CPA or $V$. cholerae outer-membrane antigens in human sera from the North American volunteer vaccine trial. ${ }^{7}$

\section{Materials and methods}

\section{$V$. cholerae strains}

Isolates of $V$. cholerae NIH 41, 569B, CVD 103 $\mathrm{HgR}$ and $3083 \mathrm{TR}^{2}$ were used. Strain 569B $\left(\right.$ tox $\left.A^{+} B^{+}\right)$ is the Classical, Inaba parent of the genetically cloned CVD 103 vaccine strain. ${ }^{3,7}$ Strain 3083 TR $^{2}$ (El Tor, Ogawa) is the virulent translucent colony type of $V$. cholerae. ${ }^{11} V$. cholerae strain $\mathrm{NIH} 41$ (Classical, Ogawa) is a National Institutes of Health reference strain. In this study, $V$. cholerae was grown in $1 \mathrm{~L}$ of low-iron " $\mathrm{T}$ " medium ${ }^{12}$ for $16 \mathrm{~h}$ at $37^{\circ} \mathrm{C}$ on a rotary shaker. Bacteria were harvested by centrifugation.

\section{Antisera}

MAbs SY15 (IgG) and NAK $258\left(\mathrm{IgG}_{1}\right)$ were prepared as previously described. ${ }^{9,10}$ MAb SY-15 was specific for $V$. cholerae LPS and MAb NAK-258 reacted specifically with CPA. MAbs were prepared by 
ammonium sulphate (final saturation $50 \%$ ) precipitation from hybridoma tissue culture supernates at $4^{\circ} \mathrm{C}$. The precipitates were dialysed for $16 \mathrm{~h}$ against three changes of phosphate-buffered saline (PBS) and stored with thimerosal $0.1 \%$ at $4^{\circ} \mathrm{C}$.

Human sera were provided by Dr J. B. Kaper (Center for Vaccine Development, University of Maryland, Baltimore, MD, USA). These sera were obtained in the course of a vaccine study in which volunteers were vaccinated by ingesting a single dose of $V$. cholerae CVD $103\left(5 \times 10^{8}\right.$ viable organisms) suspended in $120 \mathrm{ml}$ of sodium bicarbonate buffer. Vaccinees were observed for 5 days and then given tetracycline for 5 days before discharge. A control group was not vaccinated. Six months later, volunteers were challenged by ingestion of $c .10^{6}$ virulent $V$. cholerae organisms. Serum was collected before challenge and 28 days after challenge as previously described. ${ }^{7}$ For the present study, serum samples that had been stored at $-70^{\circ} \mathrm{C}$ were transported on dry ice, thawed at $22^{\circ} \mathrm{C}$ and diluted as described below.

Peroxidase-conjugated antisera were purchased from Cappel Laboratories (Organon Technica, Durham, NC, USA), reconstituted in sterile de-ionised water as recommended by the manufacturer, distributed in $50-\mu \mathrm{l}$ amounts and stored at $-70^{\circ} \mathrm{C}$. For use, sera were thawed and diluted in PBS containing Tween $201 \%$, non-fat dried milk (Carnation Co., Los Angeles, CA, USA) $5 \%$ and fetal calf serum (Rehatuin lot D82902, Armour Pharmaceutical Co., Kankakee, IL, USA) $3 \%$.

\section{Preparation of outer-membrane antigens}

The procedure of Filip et al. ${ }^{13}$ as modified by Sigel and Payne, ${ }^{12}$ was used with the following additional variations: cell pellets were removed from storage at $-70^{\circ} \mathrm{C}$ and thawed by addition of, and suspension in, $10 \mathrm{ml}$ of sodium phosphate buffer containing $\mathrm{Mg}^{2+}$. Samples were maintained at $4^{\circ} \mathrm{C}$ or submerged in an ice bath unless otherwise specified. Flagella were removed by vortex mixing the suspension vigorously with six glass beads ( $3 \mathrm{~mm}$ diameter), centrifuging the bacterial suspension at $4350 \mathrm{~g}$ and discarding the supernate containing flagella. The whole cell pellet was dispersed in $5 \mathrm{ml}$ of TEAN buffer $(5 \mathrm{mM}$ Tris, $1 \mathrm{~mm}$ EDTA, $3 \mathrm{~mm}$ azide, $200 \mathrm{~mm} \mathrm{NaCl}$ ) containing DNAase I (Sigma) $200 \mu \mathrm{g}$, and disrupted in a Branson Sonifier 450 (Branson Ultrasonics Corp., Danbury, CT, USA) with a micro-tip probe (output 6 , duty cycle of 10) for $4 \mathrm{~min}$. Unbroken whole cells were removed by centrifugation at $4350 \mathrm{~g}$ for $20 \mathrm{~min}$. The supernate was brought to a volume of $10 \mathrm{ml}$ with TEAN and centrifuged at $43700 \mathrm{~g}$ for $1 \mathrm{~h}$ at $4^{\circ} \mathrm{C}$. The resulting pellet was extracted for $30 \mathrm{~min}$ at $37^{\circ} \mathrm{C}$ with $10 \mathrm{ml}$ of TEAN containing N-sodium lauroyl sarcosine (SAR; Sigma) $1 \%$, and recovered by centrifugation at $43700 \mathrm{~g}$ for $1 \mathrm{~h}$ at $4^{\circ} \mathrm{C}$, after which the SAR extraction and centrifugation were repeated. Outer-membrane antigens were then washed with $10 \mathrm{ml}$ of TEAN, vortex mixed and centrifuged once more at $43700 \mathrm{~g}$ for $1 \mathrm{~h}$ at $4^{\circ} \mathrm{C}$. The TEAN wash and centrifugation steps were repeated. The final pellet was collected by vigorous pipetting in $0.1 \mathrm{ml}$ of TEAN buffer. Total protein was determined by a modification of the Lowry procedure ${ }^{14}$ with the addition of sodium dodecyl sulphate (SDS, BioRad) $0 \cdot 2 \%$. Outer-membrane antigen preparations were divided into portions and stored at $-70^{\circ} \mathrm{C}$.

\section{Partial purification of $C P A$}

Partially purified CPA was prepared by a modification of the above procedure. Frozen $V$. cholerae CVD $103 \mathrm{HgR}$ cells (harvested from $1 \mathrm{~L}$ of medium) were thawed and lysed by the addition of $10 \mathrm{ml}$ of TEAN buffer containing SAR $1 \%$, and $200 \mu \mathrm{g}$ of DNAase I, vortex mixed and sonicated as described above. The lysate was incubated in a water bath at $37^{\circ} \mathrm{C}$ for $30 \mathrm{~min}$ to allow complete digestion of DNA and centrifuged at $43700 \mathrm{~g}$ for $20 \mathrm{~min}$ at $4^{\circ} \mathrm{C}$. The pellet was resuspended in $10 \mathrm{ml}$ of TEAN with SAR $1 \%$ and sonicated for $10 \mathrm{~s}$. This suspension was vortex mixed, incubated at $37^{\circ} \mathrm{C}$ for $1 \mathrm{~h}$ and centrifuged at $43700 \mathrm{~g}$ for $1 \mathrm{~h}$ at $20^{\circ} \mathrm{C}$. The supernate was discarded and $10 \mathrm{ml}$ of TEAN with SDS $1 \%$ was added to the SAR-insoluble pellet. The suspension was again vigorously vortex mixed, incubated at $37^{\circ} \mathrm{C}$ for $1 \mathrm{~h}$, and centrifuged. The pellet was washed twice in this way and then analysed by SDS-PAGE.

\section{ELISA}

The procedure was similar to that described previously. ${ }^{9}$ Partially purified CPA $(10 \mu \mathrm{g} /$ well $)$ was attached to polyvinyl-chloride (PVC) ELISA plates (Dynatech Laboratories Inc., Alexandria, VA, USA) by overnight incubation in bicarbonate coating buffer $\left(\mathrm{pH} \mathrm{9.6)}\right.$ at $4^{\circ} \mathrm{C}$. The following day, non-specific binding to PVC was blocked by incubation at $22^{\circ} \mathrm{C}$ for $1 \mathrm{~h}$ with $200 \mu \mathrm{l}$ of PBS containing Tween $201 \%$, dried milk $5 \%$ and fetal calf serum $3 \%$. Excess blocking reagent was removed by washing four times with PBSTween 20. To detect human serum antibody to CPA, sera were diluted 1 in 40 with blocking buffer and 100- $\mu$ l samples were reacted with CPA-coated plates at $37^{\circ} \mathrm{C}$ for $1 \mathrm{~h}$. To establish the linearity and detection limits for the assay, serial 10-fold dilutions of CPAspecific MAb (NAK-258) (1 in 10-1 in 10000) were prepared in blocking buffer. Samples of $100 \mu \mathrm{l}$ were assayed in parallel with diluted human sera. After incubation, assay plates were washed four times with PBS-Tween 20 and incubated for $1 \mathrm{~h}$ at $37^{\circ} \mathrm{C}$ with homologous peroxidase-conjugated antisera diluted in blocking buffer. The conjugates were removed by washing four times with PBS-Tween 20 before the addition of the peroxidase substrate, 2,2'-azinobis(3-ethylbenzthiazoline sulphonic acid) (Sigma). ELISA assays were performed twice in triplicate and 
read on a Dynatech MR 700 ELISA spectrophotometer.

\section{SDS-PAGE and Western blot analysis}

Preparative electrophoresis was performed with a Hoefer SE 600 vertical slab gel electrophoresis unit. The procedure of Laemmli15 was followed. Samples of $40 \mu \mathrm{g}$ of protein/lane were mixed with dissociation buffer and boiled for $2 \mathrm{~min}$ before loading lanes for SDS-PAGE. The stacking gel $3 \%$ and running gel $12 \%$ were electrophoresed at a stacking current of $15 \mathrm{~mA}$ and running current of $20 \mathrm{~mA}$. After electrophoresis, gels were stained with silver stain (Pharmacia/LKB, Piscataway, NJ, USA).

For Western blot analysis, antigens were transferred to Imobilon P membranes by use of a Hoefer TE52 transblot apparatus, with a voltage of $0.5 \mathrm{~V}$ for $3.5 \mathrm{~h}$ at $4^{\circ} \mathrm{C}$. Lanes containing mol. wt standards and part of the antigen lane were excised from the blot, stained with Coomassie Blue $\mathrm{R}$, and de-stained according to Laemmli. ${ }^{15}$ Non-specific binding sites of the unstained Imobilon blots were blocked with PBS containing Tween $201 \%$, dried milk $5 \%$ and fetal calf serum $3 \%$, for $1 \mathrm{~h}$ at $22^{\circ} \mathrm{C}$. Blocking buffer was also used for dilutions of sera. Human sera or MAbs were diluted 1 in 20 , and blots were incubated with sera for $1 \mathrm{~h}$ at $37^{\circ} \mathrm{C}$ with gentle shaking. Afterwards, blots were rinsed three times with PBS-Tween 20 and incubated with peroxidase-conjugated affinity-purified goat antiserum to either mouse or appropriate human immunoglobulins. Blotted strips were rinsed three times with PBS-Tween 20 and exposed to the substrate, $o$ dianisidine (Sigma). Control sera and reagent controls were included for each blot. Immunoblots were performed twice for each antigen.

\section{Results}

\section{Analysis of partially purified CPA}

SDS-PAGE (fig. 1) showed that the final CPA preparation contained an $18-\mathrm{kDa}$ protein and a second protein of $>200 \mathrm{kDa}$ (fig. 1, lane C). Other fractions (fig. 1, lanes D and E), showed that the high-mol. wt protein band occurred in both SAR- and SDS-soluble preparations. Since the high-mol. wt protein could be differentiated from CPA by immunoblotting (see below), CPA was not further purified.

The detergent solubilisation procedure provided yields of $5-10 \mathrm{mg} / \mathrm{L}$ of cells. CPA was isolated with similar yields from $V$. cholerae strains 569B, 3083TR ${ }^{2}$ and NIH 41. Growth of bacteria in low-iron " $\mathrm{T}$ " medium increased the yields of CPA and reduced contamination with LPS and other outer-membrane antigens. CPA preparations sometimes contained two additional protein bands of $c .72 \mathrm{kDa}$ and $32 \mathrm{kDa}$ that were removed from the CPA preparation by the first SAR extraction and centrifugation (fig. 1, lane B); otherwise, this material co-purified with CPA.
Comparison of CPA, outer-membrane antigens and LPS within gels showed that the band corresponding to lipid $\mathrm{A}(c .12 \mathrm{kDa})$ stained bright orange; the higher mol. wt repeating subunits of LPS stained brilliant yellow; and CPA stained a silver-grey colour. During the SAR solubilisation step, most LPS was removed from the CPA preparation (fig. 1, lane D). LPS was

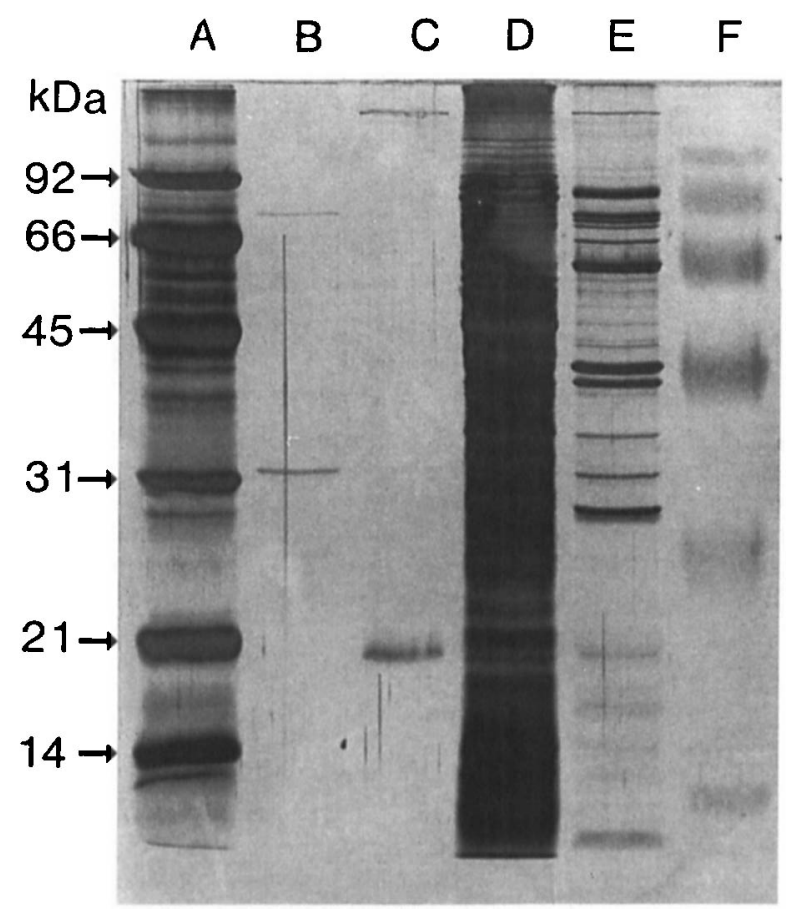

Fig. 1. SDS-PAGE comparison of SAR-SDS purified CPA with purified $V$. cholerae LPS and outer-membrane antigens, stained with silver stain. Lane A, mol. wt markers; B, 72-kDa and 32-kDa outermembrane antigens; C, SAR-insoluble, SDS-insoluble antigens (CPA is the 18 -kDa protein); D, SAR-soluble proteins; E, SARinsoluble, SDS-soluble outer-membrane antigens; F, V. cholerae LPS.

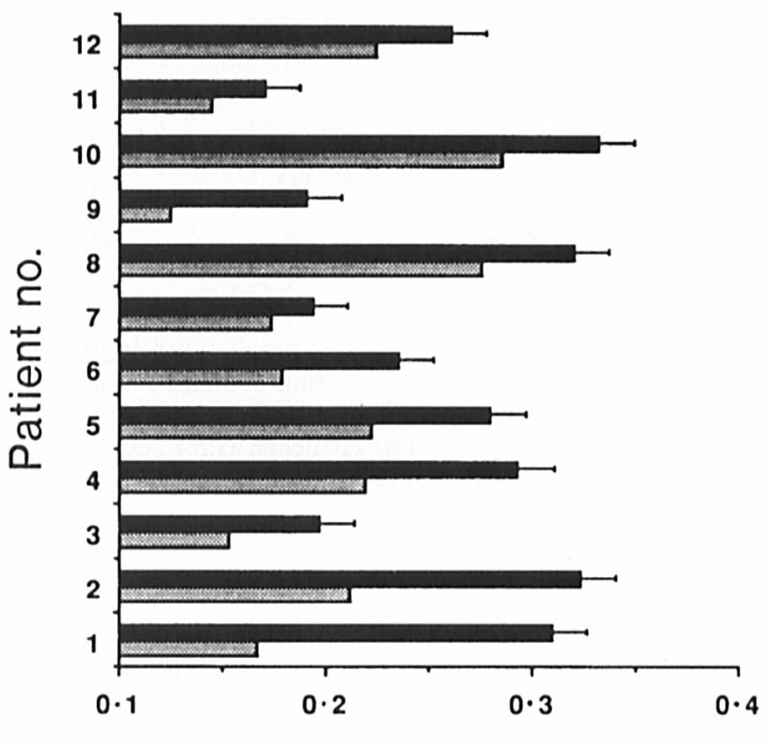

ELISA OD value

Fig. 2. CPA-ELISA of human sera. ELISA reactions of paired volunteers' sera were diluted 1 in 40 and reacted with purified CPA. Subject nos 1-10 were challenged with $V$. cholerae, and nos 11 and 12 were unchallenged controls. Error bars represent one standard deviation above the mean value $(n=6)$ observed in sera obtained before challenge. 


\section{Controls Patients}

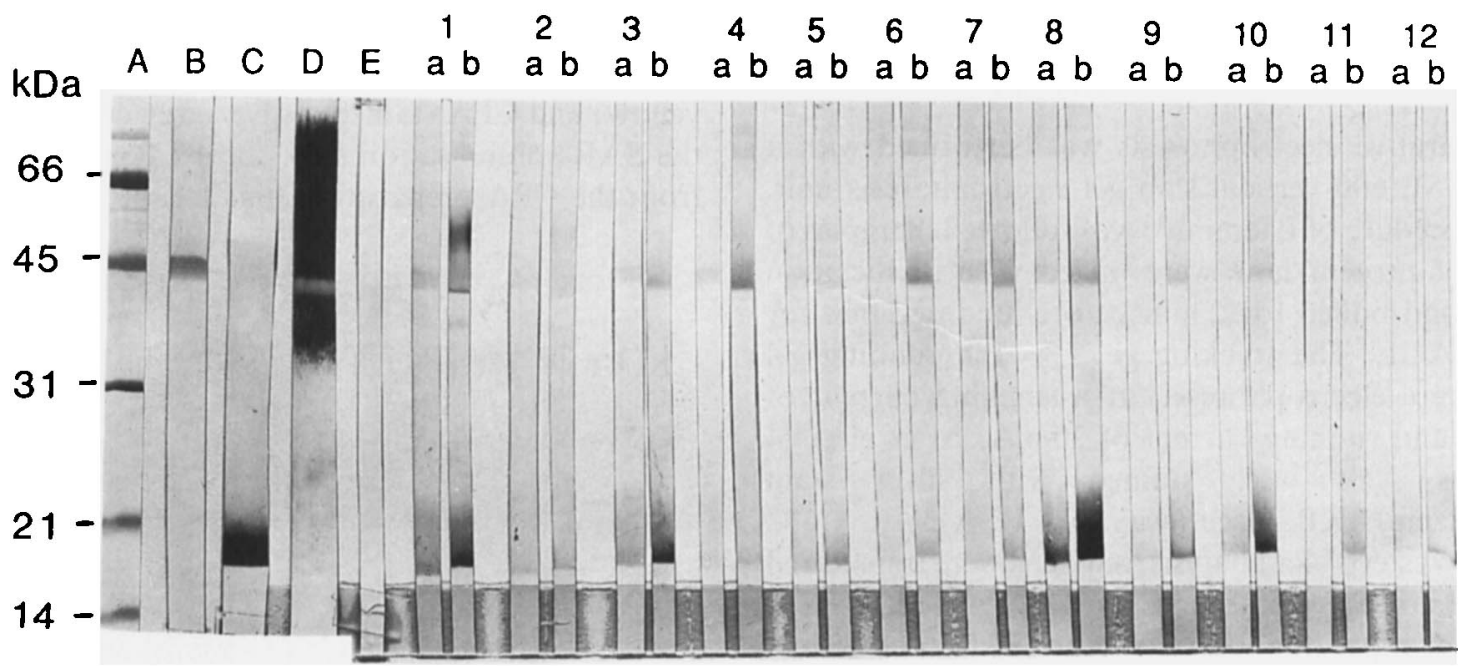

Fig. 3. Western immunoblot of human sera reacted with outer-membrane antigens prepared from $V$. cholerae strain 569B grown under conditions of low iron availability. Lane A, Coomassie Blue R stained mol. wt standards; B, Coomassie Blue R stain of Imobilon-transferred antigens; C, immunoblot reacted with MAb NAK-258 (anti-CPA); D, immunoblot reacted with MAb SY-15 (anti-LPS); E, immunoblot reagent control. For all sera: lane $\mathrm{a}=$ serum before challenge with $V$. cholerae; lane $\mathrm{b}=$ serum 28 days after challenge. Subjects $1-5$ were challenged with $10^{6} \mathrm{~V}$. cholerae N16961, El Tor:Inaba; and subjects 6-10 were challenged with $2 \times 10^{7} \mathrm{~V}$. cholerae $569 \mathrm{~B}$, Classical: Inaba. Sera 11 and 12 were from unchallenged subjects.

\section{Controls}

\section{Patients}

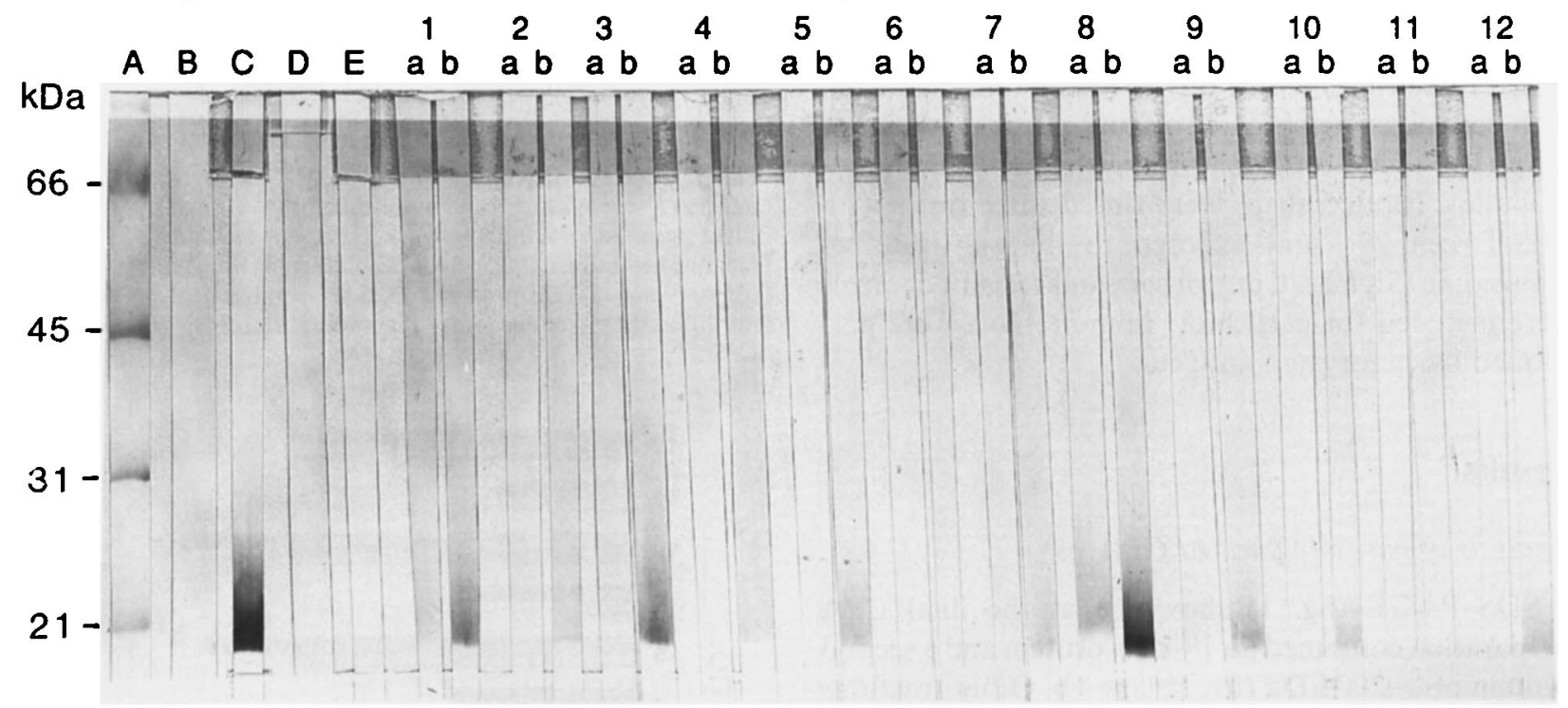

Fig. 4. Western immunoblot of human sera reacted with CPA prepared from $V$. cholerae strain CVD 103-HgR grown under conditions of low iron availability. Lane $\mathbf{A}$, Coomassie Blue $\mathbf{R}$ stained mol. wt standards; $\mathbf{B}$, Coomassie Blue $\mathbf{R}$ stain of Imobilon-transferred antigens; $\mathbf{C}$, immunoblot reacted with MAb NAK-258 (anti-CPA); D, immunoblot reacted with MAb SY-15 (anti-LPS); E, immunoblot reagent control. For all sera: lane $\mathrm{a}=$ serum before challenge with $V$. cholerae; lane $\mathrm{b}=$ serum 28 days after challenge. Subjects $1-5$ were challenged with $10^{6}$ $V$. cholerae N16961, El Tor:Inaba; and subjects 6-10 were challenged with $2 \times 10^{7} \mathrm{~V}$. cholerae 569B, Classical:Inaba. Sera 11 and 12 were from unchallenged subjects.

not detected by silver stain in outer-membrane antigens (fig. 1, lane E), or in CPA preparations (fig. 1, lane C). CPA did not stain with Coomassie Blue $\mathbf{R}$ and stained weakly with silver stain. Therefore, the gel in fig. 1 was "over-developed" so that proteins in lanes B and $C$ could be photographed. For this reason some lanes appeared to have more protein than others; however, each lane contained the same amount of protein.

\section{ELISA}

All human sera that were tested by ELISA showed some reactivity with CPA (fig. 2). The ELISA values of sera obtained after challenge with $V$. cholerae were more than two standard deviations above the mean value observed before challenge. An increase in serum ELISA reactivity was observed in the serum of all subjects after challenge, except subjects 7 and 11 . 


\section{Western blotting}

Western blots of outer-membrane antigens prepared from two $V$. cholerae strains of different biotype showed similar results with sera from volunteers. Sera from four of the 10 volunteers reacted weakly with outer-membrane antigens before challenge with $V$. cholerae. Six sera produced a stronger reaction with the $18-\mathrm{kDa}$ antigen than with other outer-membrane antigens after challenge. The remaining sera reacted weakly with the $18-\mathrm{kDa}$ antigen and with other outermembrane antigens (fig. 3). No reactions were observed in immunoblots of pre-challenge sera obtained from subjects 11 and 12 .

MAbs that were specific for CPA and LPS were included as controls in the immunoblots (fig. 3, lanes C and D). Immunoblots that were exposed to MAb SY15 (fig. 3, lane D), showed bands coinciding with the high-mol. wt repeating subunits of LPS. Some of the sera that were treated with outer-membrane antigens showed weak reacting bands coinciding with LPS. Furthermore, the MAb controls provided evidence that the serum reactivity of CPA was separate and distinct from that of LPS. For instance, MAb SY-15 did not react with CPA in the immunoblots, and vice versa, MAb NAK-258 did not react with LPS in immunoblots of outer-membrane antigens (fig. 3).

Sera from volunteers were tested with the purified $18-\mathrm{kDa}$ protein by immunoblotting to further demonstrate the independent reactivity of serum antibody with CPA (fig. 4). Eight of 10 sera obtained after challenge with $V$. cholerae, reacted with purified CPA. Serum from one of the unchallenged subjects also gave a positive reaction with CPA and outer-membrane antigens.

\section{Discussion}

The study of $V$. cholerae outer-membrane antigens is difficult since various physiological conditions regulate antigen expression. For instance, some antigens are expressed only in vivo, ${ }^{16,17}$ or in response to lowiron conditions in culture. ${ }^{12,17}$ Other proteins, such as the toxin co-regulated pilus, the $52-\mathrm{kDa} V$. cholerae outer-membrane protein and cholera toxin, are osmoregulated. ${ }^{18,19}$ In this study, vibrios grown under conditions of low iron availability were used.

In the North American cholera vaccine trial ${ }^{7}$ from which sera were obtained for the present studies, one group of subjects was vaccinated with $V$. cholerae CVD 103 and another group was unvaccinated. Six months later, volunteers were challenged with virulent $V$. cholerae. Sera were collected 10 days before and 28 days after challenge. Vaccine efficacy in subjects who received CVD $103 \mathrm{HgR}$ was $62 \%$, and at six months
$83 \%$ of the volunteers showed a rise (ELISA OD $\geqslant 0 \cdot 2$ ) in serum titre to cholera toxin, with a mean peak titre of $21 .^{7}$

In the present study, sera from unvaccinated convalescent subjects reacted with purified CPA and other outer-membrane antigens. Increased Western blot reactions of sera with purified CPA strongly indicated that infection stimulated CPA antibody in volunteers. ELISA of sera diluted 1 in 40 showed that $80 \%$ of unvaccinated subjects exhibited a rise in serum antibody to CPA after challenge with $V$. cholerae. The high-mol. wt antigen was not reactive in Western blots, but it may have influenced ELISA results by increasing reactivity. Pre-existing serum reactivity with CPA and outer-membrane antigens occurred with the serum of some subjects before challenge and in some unchallenged subjects. However, in the original study from which these sera were obtained, pre-immune ELISA cross-reactivity with the vaccine preparations was not reported, ${ }^{7}$ but similar post-vaccination, prechallenge reactivity was seen in Western blots (J. B. Kaper, personal communication).

To examine the possibility that binding of CPA with serum IgG was non-specific, the ELISA and Western blot results were compared. If the positive cut-off value of the ELISA was lowered to $0.15 \mathrm{OD}$, the results from Western blots and ELISA assays were in complete agreement. In Western blots, control sera nos. 11 and 12 and the pre-challenge sera all reacted similarly. We conclude from the two test results that the immunoblots gave specific results whereas the ELISA was quantitative but exhibited low-level nonspecificity.

In a previous study, the serum IgM or IgA response of volunteers vaccinated with $V$. cholerae CVD 101 were measured by ELISA with whole vibrios, vibrio lysates, outer-membrane antigens, LPS, cholera toxin and the toxin co-regulated pilus. ${ }^{6}$ Among volunteers giving a positive test, a serological response occurred in the chronological order: cholera toxin before outermembrane antigens before whole vibrios or LPS before vibrio lysate before toxin co-regulated pilus. The CPA component of the response to outer-membrane antigens was not investigated in that study, and Western blots were not done.

The present results provide evidence that the expression of CPA by challenge strains stimulates serum antibody which recognises CPA and that this reactivity is independent of biotype and serotype. The vibrio strains used in this study all contained CPA but more studies are needed to establish the role of CPA in cholera immunity. The biochemical identity of CPA and its prevalence in other bacteria is presently undergoing study.

We thank Dr J. B. Kaper for providing human sera for this study. We also thank the Veterans Administration Medical Center of Louisville, KY, for their support of this work. 


\section{References}

1. Cash RA, Music SI, Libonati JP, Craig JP, Pierce NF, Homick RB. Response of man to infection with Vibrio cholerae. II Protection from illness afforded by previous disease and vaccine. J Infect Dis $1974 ; 130$ : 325-333.

2. Clements ML, Levine MM, Young CR et al. Magnitude, kinetics, and duration of vibriocidal antibody responses in North Americans after ingestion of Vibrio cholerae. J Infect Dis $1982 ; 145$ : 465-473.

3. Kaper JB, Lockman H, Baldini MM, Levine MM. Recombinant nontoxinogenic Vibrio cholerae strains as attenuated cholera vaccine candidates. Nature $1984 ; 308$ : 655-658.

4. Levine MM, Nalin DR, Craig JP et al. Immunity of cholera in man: relative role of antibacterial versus antitoxic immunity. Trans R Soc Trop Med Hyg 1979; 73: 3-9.

5. Levine MM, Black RE, Clements ML et al. Evaluation in humans of attenuated Vibrio cholerae El Tor Ogawa strain Texas Star-SR as a live oral vaccine. Infect Immun 1984; 43: $515-522$

6. Levine MM, Kaper JB, Herrington D et al. Volunteer studies of deletion mutants of Vibrio cholerae $\mathrm{O} 1$ prepared by recombinant techniques. Infect Immun 1988; 56: 161-167.

7. Levine MM, Herrington D, Losonsky G et al. Safety, immunogenicity, and efficacy of recombinant live oral cholera vaccines, CVD 103 and CVD 103-HgR. Lancet 1988; 2: 467-470.

8. Migasena S, Pitisuttitham P, Prayurahong B et al. Preliminary assessment of the safety and immunogenicity of live oral cholera vaccine strain CVD $103-\mathrm{HgR}$ in healthy Thai adults. Infect Immun 1989; 57: 3261-3264.

9. Sciortino CV, Yang Z, Finkelstein RA. Monoclonal antibodies to outer membrane antigens of Vibrio cholerae. Infect Immun 1985; 49: 122-131.

10. Sciortino CV. Protection against infection with Vibrio cholerae by passive transfer of monoclonal antibodies to outer membrane antigens. $J$ Infect Dis 1989; 160: 248-252.

11. Holmes RK, Vasil ML, Finkelstein RA. Studies on toxigenesis in Vibrio cholerae. III. Characterization of non-toxinogenic mutants in vitro and in experimental animals. J Clin Invest 1975; 55: 551-560.

12. Sigel SP, Payne SM. Effect of iron limitation on growth, siderophore production, and expression of outer membrane proteins of Vibrio cholerae. J Bacteriol 1982; 150: $148-155$.

13. Filip C, Fletcher G, Wulff JL, Earhart CF. Solubilization of the cytoplasmic membrane of Escherichia coli by the ionic detergent sodium-lauryl sarcosinate. J Bacteriol 1973; 115: 717-722.

14. Lowry OH, Rosebrough NJ, Farr AL, Randall RJ. Protein measurement with the folin phenol reagent. $J$ Biol Chem 1951; 193: 265-275.

15. Laemmli UK. Cleavage of structural proteins during the assembly of the head of bacteriophage T4. Nature 1970; 227: 680-685.

16. Jonson G, Svennerholm A-M, Holgren J. Vibrio cholerae expresses cell surface antigens during intestinal infection which are not expressed during in vitro culture. Infect Immun 1989; 57: 1809-1815.

17. Sciortino CV, Finkelstein RA. Vibrio cholerae expresses ironregulated outer membrane proteins in vivo. Infect Immun $1983 ; 42$ : 990-996.

18. Miller VL, Mekalanos JJ. A novel suicide vector and its use in construction of insertion mutations: Osmoregulation of outer membrane proteins and virulence determinants in Vibrio cholerae requires toxR. J Bacteriol 1988; 170: 2575-2583.

19. Sciortino CV. Sodium regulation of $V$. cholerae outer membrane proteins and enterotoxin production. In: Lambert PD (ed) Proceedings of the 23rd US-Japan Conference on Cholera, NIAID, NIH. 1987: 96. 